\title{
Caracterización físico-química y microbiológica del lactosuero del queso Paipa
}

\section{Physicochemical and microbiological characteristics of the Paipa cheese whey}

Fecha de recepción: 1 de febrero de 2018

Fecha de aprobación: 2 de mayo de 2018
Ricardo Enrique López-Barreto ${ }^{1}$ Mónica Liliana Becerra-Jiménez² Luis Miguel Borrás-Sandoval ${ }^{3}$

DOI: http://doi.org/10.19053/01228420.v15.2

\section{Resumen}

El queso Paipa es el único queso madurado que se produce en Colombia; su lactosuero, al ser desechado de manera inadecuada, genera un problema ambiental, por lo que es necesario plantear opciones para industrializarlo y evitar así esta situación; adelantar su caracterización físico-química y microbiológica contribuye a este propósito. Se analizaron muestras de lactosuero de tres plantas representativas de queso Paipa; los promedios evaluados presentaron diferencias estadísticas significativas $(P \leq 0,01)$ en los parámetros de calorías, carbohidratos, humedad, grasa, proteína, aerobios mesófilos, mohos, bacterias ácido lácticas $(\mathrm{BAL})$ y levaduras. Los resultados promedios de las muestras analizadas tienen valores en el rango de clasificación como suero dulce, con un pH promedio de 5,7, y lactosa de 5,1\%; sin embargo, estos no presentaron buena calidad sanitaria. Las bondades del lactosuero del queso Paipa en su composición, en lo referente a los promedios en proteína $(0,71 \pm 0,12)$, cenizas $(0,42)$, grasa $(0,5 \pm 0,14)$ y sus recuentos en levaduras en promedio de $38 \times 10^{2}$ y de BAL de $10,7 \times 10^{4}$, lo posicionan como alternativa para su uso como medio de cultivo y materia prima de procesos biotecnológicos en la elaboración de distintos productos en la industria alimentaria.

Palabras clave: bacterias ácido lácticas; lactosuero; levaduras; queso Paipa.

1 Universidad Pedagógica y Tecnológica de Colombia (Tunja-Boyacá, Colombia). ORCID: 0000-0001-8829-1807. ricardo. lopez@uptc.edu.co.

2 Ph. D (C). Universidad Pedagógica y Tecnológica de Colombia (Tunja-Boyacá, Colombia). ORCID: 0000-0002-02759008. monica.becerra@uptc.edu.co.

3 Ph.D. Universidad Pedagógica y Tecnológica de Colombia (Tunja-Boyacá, Colombia). ORCID: 0000-0002-3284-027X. luis.borras@uptc.edu.co.

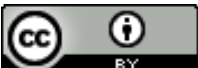




\begin{abstract}
Paipa cheese is the only ripened cheese in Colombia. The whey of Paipa cheese can be considered an environmental problem; therefore, its characterization may contribute to propose options for its industrialization, and to guarantee that the whey is discarded in proper manners. The physicochemical and microbiological characteristics of samples of whey from three representative plants of Paipa cheese were analyzed. The averages evaluated showed significant statistical differences $(P \leq 0,01)$ in the following parameters: calories, carbohydrates, humidity, fat, protein, mesophilic aerobes, molds, lactic acid bacteria $(\mathrm{BAL})$, and yeast. The average results of the analyzed samples had values within the classification range of sweet whey, with an average $\mathrm{pH}$ of 5,7 and lactose of 5,1\%; however, they lacked good sanitary quality. The benefits of the whey composition, particularly in regards to the averages in protein $(0,71 \pm 0,12)$, ashes $(0,42)$ and fat $(0,5 \pm 0,14)$, and its counts in yeast $\left(38 \times 10^{2}\right.$ on average $)$ and $\mathrm{BAL}\left(10,7 \times 10^{4}\right.$ on average) position the Paipa cheese whey as an alternative as a culture medium and raw material for biotechnological processes in the production of different products in the food industry.
\end{abstract}

Keywords: lactic acid bacteria; Paipa cheese; whey; yeast.

\title{
Para citar este artículo:
}

López-Barreto RE., Becerra-Jiménez ML., Borrás-Sandoval LM. Caracterización físico-química y microbiológica del lactosuero del queso Paipa. Ciencia y Agricultura. 2018; 15(2): 99-106. 


\section{Introducción}

El queso Paipa es el único queso madurado con denominación de origen de Colombia; es elaborado, principalmente, en los municipios de Paipa y Sotaquirá, en el departamento de Boyacá, con leche sin pasteurizar, lo que le otorga sus características físico-químicas y sensoriales propias, pero también puede traerle muchos problemas sanitarios, por lo que se recomienda un tiempo de maduración mínimo de 30 días. Es un queso amasado prensado y madurado, con un contenido de humedad del $60 \%$ y $41 \%$ de grasa. Es de color amarillo claro, ligeramente brillante, con corteza corrugada y con ojos. textura semidura, aroma rancio suave y sabor ácido moderado.

Como subproducto de este proceso se obtiene el lactosuero, que ha sido considerado un desecho y es vertido en efluentes y suelos, generando problemas ambientales, dado que presenta un alto poder contaminante por su elevado contenido en materia orgánica, en particular de lactosa, la principal responsable de la contaminación, debido a su capacidad para actuar como sustrato de fermentación microbiana (2); sin embargo, en los últimos años se ha desarrollado una tecnología para su aprovechamiento, transformándolo en un componente con gran potencial dentro de la industria (1).

Existen dos tipos de suero: dulce y ácido. El primero se obtiene de la coagulación enzimática de la leche, y el segundo se produce por acidificación de ácidos orgánicos que se utilizan en el proceso de elaboración de queso fresco. Ambos sueros presentan diferencias en su composición; en general, el dulce tiene un $\mathrm{pH}$ más elevado, mayor contenido de proteínas, lactosa, lípidos y menor cantidad de calcio y fósforo (3). El suero dulce se obtiene al Ilevarse a cabo la coagulación por acción enzimática, presenta un $\mathrm{pH}$ de 5.6 y se obtiene al elaborar queso Chihuahua, Cheddar y manchego, entre otros (4). En el municipio de Paipa se cuenta con alta disponibilidad de lactosuero derivado del queso Paipa, el cual puede ser utilizado como materia prima en productos para el consumo, disminuyendo notablemente su impacto ambiental y las problemáticas que pueda ocasionar.
Las principales problemáticas identificadas en la cadena de lácteos en Boyacá están relacionadas con bajos niveles de competitividad, así como con la escasa existencia de empresas generadoras de valor agregado en la producción de derivados lácteos (5). Según el PEDCTI (Proyectos en CTel para el sector agroindustrial de Boyacá - 2022), capítulo III, el estudio del manejo y aprovechamiento de la biomasa residual es una temática que el departamento debe desarrollar (5). El suero lácteo contiene alrededor del 50 por ciento de los nutrientes de la leche (proteínas solubles, lactosa, vitaminas y sales minerales), constituyendo una reserva alimentaria de alto valor nutricional que brinda una oportunidad de desarrollo al sector agroindustrial y ampliaría la base de consumo de derivados lácteos en el país, convirtiéndolo en un sustrato disponible de bajo costo útil para la industria colombiana (6).

Es por esto que la caracterización físico-química y microbiológica del lactosuero de queso Paipa es un paso importante para la utilización de este subproducto de la industria láctea en distintos procesos industriales, tanto en la alimentación humana como animal. Autores indican que la cantidad y la composición del lactosuero son los condicionantes de la elección del proceso adecuado para su transformación y del tipo de productos por obtener, así como de las características nutritivas y el destino de los subproductos derivados del tratamiento tecnológico del lactosuero (7).

\section{Materiales y métodos}

Se analizaron parámetros físico-químicos y microbiológicos de lactosuero proveniente de tres plantas representativas productoras de queso Paipa, ubicadas en el municipio de Paipa, departamento de Boyacá. Se contó con 9 muestras de suero que fueron colectadas, etiquetadas y transportadas con refrigerante a los laboratorios certificados, y se almacenaron a $4{ }^{\circ} \mathrm{C}$ hasta el momento de su análisis físico-químico $(\mathrm{pH}$, materia seca, cenizas, proteína, lactosa) y microbiológico (cuenta total de coliformes, bacterias mesófilas aerobias, mohos, levaduras y bacterias ácido lácticas). Todos los análisis se realizaron por triplicado, en tres días de producción diferentes, en el lapso de 30 días; en el día 1, en el 
día 15 y en el día 30 del mes, con el fin de tener representatividad en los datos durante la producción de queso en las plantas. Se tomaron muestras del primer desuere antes del salado de la cuajada y se enviaron a los laboratorios para su análisis.

\section{A. Análisis físico-químico}

Las variables que se tuvieron en cuenta fueron $\mathrm{pH}$, materia grasa, lactosa, cenizas y proteína. Al respecto, las muestras fueron remitidas al laboratorio certificado de análisis de alimentos de la Universidad Pedagógica y Tecnológica de Colombia, en donde se utilizaron los siguientes protocolos para efectuar los análisis fisicoquímicos: la determinación de $\mathrm{pH}$ se realizó mediante el potenciómetro; el contenido de materia grasa, expresado en (g/100 g), fue determinado por medio de hidrólisis ácida, mediante el protocolo de Gerber; el de cenizas, por el método de calcinación; el de proteína, a través del método Kjeldahl, y el de lactosa, mediante HPLC.

\section{B. Análisis microbiológico}

El análisis microbiológico del lactosuero se realizó en un laboratorio certificado de Control Microbiológico ubicado en Boyacá, Colombia, aplicando los protocolos establecidos en las normas para el análisis de derivados lácteos, así: para aerobios mesófilos (UFC/mL), AOAC 966.23.C: 2001; para Bacillus cereus (UFC/ml), ISO7932:1994; para coliformes totales y fecales (NMP), ICMSF NMP:2000; para esporas de Clostridium Sulfito reductor (UFC/ $\mathrm{ml}$ ), ISO 15213: 2003; mohos y levaduras (UFC/ ml), ISO 7954: 2002; Salmonella, AS5013.10: 2009; Staphylococus aureus coagulasa positiva (UFC/ml), NF V 08-057-1:2004, y bacterias ácido lácticas (UFC/ml), NTC5034: 2002.

\section{Análisis estadístico}

El análisis de los promedios de los parámetros del lactosuero que se tuvieron en cuenta se realizó mediante la prueba de análisis de varianza (ANAVA). La comparación de medias se realizó con la prueba de Tukey $(p<0,05)$. En las pruebas estadísticas se utilizó el programa SPSS Statistics versión 20.

\section{Resultados y discusión}

\section{A. Análisis físico-químico:}

En el análisis físico-químico que se realizó al lactosuero de queso Paipa se presentaron diferencias estadísticas significativas $(P \leq 0,01)$ entre las plantas productoras en los parámetros de Calorías, Carbohidratos, Humedad, Grasa y Proteína (Tabla I).

Tabla I. Análisis físico-químico del lactosuero de queso Paipa.

\begin{tabular}{|l|c|c|c|}
\hline \multirow{2}{*}{\multicolumn{1}{c|}{ PARÁMETRO }} & \multicolumn{3}{c|}{ PLANTAS DE QUESO PAIPA } \\
\cline { 2 - 4 } & LOS ALISOS & LA PRADERA & CARTAGENA \\
\hline $\begin{array}{l}\text { ACTIVIDAD DE AGUA } \\
\left(\text { AW/T }{ }^{\circ} \mathbf{C}\right) \mathbf{1 8 , 8}{ }^{\circ} \mathbf{C}\end{array}$ & $0,94 \mathrm{a}$ & $0,96 \mathrm{a}$ & $0,93 \mathrm{a}$ \\
\hline PH & $5,6 \mathrm{a}$ & $5,7 \mathrm{a}$ & $5,8 \mathrm{a}$ \\
\hline LACTOSA (\%) & $5,1 \mathrm{a}$ & $5,2 \mathrm{a}$ & $5 \mathrm{a}$ \\
\hline CALORÍAS (Kcal/100 g) & $28,12 \mathrm{c}$ & $31,28 \mathrm{~b}$ & $27,94 \mathrm{a}$ \\
\hline CARBOHIDRATOS (\%) & $5,37 \mathrm{~b}$ & $5,75 \mathrm{a}$ & $5,23 \mathrm{c}$ \\
\hline HUMEDAD (\%) & $93,15 \mathrm{a}$ & $92,56 \mathrm{~b}$ & $93,22 \mathrm{a}$ \\
\hline CENIZA (\%) & $0,42 \mathrm{a}$ & $0,42 \mathrm{a}$ & $0,42 \mathrm{a}$ \\
\hline GRASA (\%) & $0,36 \mathrm{c}$ & $0,64 \mathrm{a}$ & $0,5 \mathrm{~b}$ \\
\hline PROTEÍNA (\%) & $0,85 \mathrm{a}$ & $0,63 \mathrm{~b}$ & $0,65 \mathrm{~b}$ \\
\hline
\end{tabular}

Promedios seguidos de letras distintas presentan diferencias significativas según prueba de Tukey

$$
(P \leq 0,01) \text {. }
$$


1) $\mathbf{p H}$ en lactosuero de queso Paipa: Los valores de $\mathrm{pH}$ logrados en las muestras de lactosuero analizadas fueron similares entre las plantas de queso evaluadas, con un promedio de 5,7. Este pH es característico de sueros obtenidos de la coagulación enzimática de la leche, lo que obedece, seguramente, a que dicho suero proviene de un queso elaborado con leche sin pasteurizar. El valor del $\mathrm{pH}$ no está contemplado en las especificaciones del Ministerio de Salud de Colombia (8); sin embargo, el pH que clasifica al lactosuero como ácido debería ser $<4,5(9)$, y un lactosuero dulce es pobre en ácido láctico y su pH es > 5,8 (10); los lactosueros analizados en el presente estudio se pueden clasificar como dulces, pero posiblemente con una concentración aumentada de ácido láctico.

2) Lactosa en lactosuero de queso Paipa: Para los contenidos de lactosa, el Ministerio de Salud de Colombia reporta valores mínimos de 4,5\% (8); el contenido de lactosa en lactosuero de queso Paipa fluctúa entre $5 \%$ y 5,2\%; entonces, las plantas se encuentran dentro de las especificaciones de la resolución, con un contenido de 5,1\% en promedio. El intervalo reportado para la concentración de lactosa en suero es de 3,8 \% a 5,3\% (11); en 2010, un estudio (10) encontró que el contenido de lactosa en suero dulce fluctuó desde $3,89 \%$ hasta $6,81 \%$, con un promedio de 4,648 \%, dependiendo del tipo de queso; en donde, para quesos con coagulación ácida los contenidos de lactosa fueron menores, y para coagulación enzimática, mayores.

Algunos autores sostienen que la concentración de lactosa en suero destinado para uso industrial es de mínimo $4 \%$ de lactosa (11); valores menores se relacionan con la capacidad de transformarse en ácido láctico a medida que avanza el tiempo de recolección del suero, y por ello es necesario un tratamiento adecuado y rápido en el enfriamiento y eliminación de partículas de queso para evitar la transformación de la lactosa en ácido láctico (12).

\section{3) Materia grasa en lactosuero de queso Paipa: El} intervalo de referencia que se utilizó para el análisis en contenido de grasa es de $0,1 \%-0,5 \%$ (11). Los contenidos de grasa fluctuaron desde $0,36 \%$ hasta $0,64 \%$, con un promedio de $0,5 \%$ en lactosuero de queso Paipa. Se presentaron diferencias estadísticas significativas $(P \leq 0,01)$ entre las plantas productoras de queso. El mayor porcentaje de grasa se obtuvo en la planta La Pradera, y el menor, en la planta Los Alisos. Ninguna de las muestras de lactosuero analizadas presentó contenidos menores a $0,1 \%$ de grasa.

El suero es especialmente rico en materia grasa, proteína, lactosa y sales minerales; también, en riboflavina y ácido pantoténico (11). El contenido de grasa en el suero varía en función de la calidad composicional de la leche y del tipo de trabajo mecánico antes y después de la coagulación del líquido; encontrándose que altos contenidos de grasa y caseína en el suero traen consigo disminución en el rendimiento quesero (1).

4) Proteína y cenizas en lactosuero de queso Paipa: El contenido de proteína está entre $0,63 \%$ y 0,85 $\%$, siendo el valor más alto el correspondiente a la planta Los Alisos, presentando diferencias estadísticas significativas $(P \leq 0,01)$ frente a las otras dos plantas de esta investigación, teniendo un promedio total de 0,71\% de proteína. De acuerdo con el Ministerio de Salud de Colombia, los contenidos de proteína en suero líquido pueden estar en valores superiores a $0,7 \%(8)$, aunque algunos autores reportan contenidos en promedio de proteína del $0,3 \%$ y valores máximos hasta del 0, 8\% (11).

Investigaciones relacionadas con la caracterización fisicoquímica de sueros provenientes de quesos frescos típicos mexicanos reportan contenidos proteicos en promedio de 0,266 \% (10). También en México se encontraron, en promedio, contenidos de proteína en suero de 0,83 \% y valores de $1,26 \%$ para suero obtenido de quesos tipo Oaxaca y panela (13).

Las cenizas constituyen uno de los elementos más representativos del suero; junto con la proteína, tienen potencialidad para su uso industrial (11). En relación con el contenido de cenizas, el valor promedio fue $0,42 \%(4,2 \mathrm{~g} / \mathrm{L})$; valores reportados con anterioridad indican que el rango en el contenido de cenizas en suero dulce varía entre 5 y $5,2 \mathrm{~g} / \mathrm{L}$ (14). 


\section{B. Análisis microbiológico}

El análisis microbiológico realizado al lactosuero de queso Paipa arrojó diferencias estadísticas sig- nificativas $(P \leq 0,01)$ entre las plantas productoras, en los parámetros de Aerobios mesófilos, Mohos, Bacterias Ácido Lácticas (BAL) y Levaduras (Tabla II).

Tabla II. Análisis microbiológico del lactosuero de queso Paipa.

\begin{tabular}{|l|c|c|c|}
\hline \multirow{2}{*}{ PARÁMETRO } & \multicolumn{2}{c|}{ PLANTAS DE QUESO PAIPA } \\
\cline { 2 - 4 } & LOS ALISOS & LA PRADERA & CARTAGENA \\
\hline AEROBIOS MESÓFILOS (UFC/mL) & $11 \times 10^{5} \mathrm{C}$ & $13 \times 10^{5} \mathrm{~b}$ & $16 \times 10^{5} \mathrm{a}$ \\
\hline Bacillus cereus (UFC/mL) & $<10 \mathrm{a}$ & $<10 \mathrm{a}$ & $<10 \mathrm{a}$ \\
\hline COLIFORMES FECALES (NMP/mL) & $>1100 \mathrm{a}$ & $>1100 \mathrm{a}$ & $>1100 \mathrm{a}$ \\
\hline COLIFORMES TOTALES (NMP/mL) & $>1100 \mathrm{a}$ & $>1100 \mathrm{a}$ & $>1100 \mathrm{a}$ \\
\hline Esporas Clostridium sulfito reductor (UFC/mL) & $<10 \mathrm{a}$ & $<10 \mathrm{a}$ & $<10 \mathrm{a}$ \\
\hline LEVADURAS (UFC/mL) & $51 \times 10^{2} \mathrm{a}$ & $14 \times 10^{2} \mathrm{~b}$ & $49 \times 10^{2} \mathrm{a}$ \\
\hline MOHOS (UFC/mL) & $20 \mathrm{c}$ & $80 \mathrm{a}$ & $40 \mathrm{~b}$ \\
\hline Salmonella sp. (A-P/25mL) & ausencia & Ausencia & Ausencia \\
\hline Staphylococus aureus coagulasa positiva (UFC/mL) & $<10 \mathrm{a}$ & $<10 \mathrm{a}$ & $<10 \mathrm{a}$ \\
\hline BACTERIAS ÁCIDO LÁCTICAS (UFC/mL) & $6 \times 10^{4} \mathrm{~b}$ & $10 \times 10^{4} \mathrm{~b}$ & $16 \times 10^{4} \mathrm{a}$ \\
\hline
\end{tabular}

*NMP: Número más probable, **UFC: Unidades Formadoras de Colonia, ${ }^{* * *}(\mathrm{~A}-\mathrm{P})$ : Ausencia-

Presencia. Promedios en las filas seguidos de letras distintas presentan diferencias significativas según prueba de Tukey $(\mathrm{P} \leq 0,01)$.

Las muestras evaluadas cumplen con los parámetros microbiológicos del Ministerio de Salud de Colombia (8), exceptuando Coliformes Totales, Coliformes Fecales, Aerobios mesófilos y Levaduras. Un recuento alto de unidades formadoras de colonias (UFC) de estos parámetros en un alimento o subproducto indica que, probablemente, ha sido conservado en condiciones de tiempo y temperatura que han permitido el desarrollo de microorganismos; influye en esto, además, la mala higiene de los utensilios y del personal, condiciones ambientales inadecuadas, infraestructura deficiente o la calidad microbiológica de la materia prima utilizada en la elaboración del alimento o en el subproducto (15). Esto se puede deber a que la leche con la cual se elabora el queso Paipa carece de proceso de pasteurización; además, indicaría que la leche utilizada en la elaboración del queso Paipa presenta un deficiente manejo, ya que, en el momento de la mezcla de la leche en la recolección, almacenamiento y transporte, puede presentarse contaminación, lo cual indicaría que estos procesos pueden tener falencias en su estandarización y ejecución.

\section{Levaduras y $B A L$}

En esta investigación se encontraron ventajas que ofrece el lactosuero de queso Paipa respecto a las cantidades de Levaduras y BAL presentes en él: promedios de $38 \times 10^{2}$ de Levaduras y de $10,7 \times$ $10^{4}$ de BAL (Figura 1). Estos microorganismos podrían ser, en su mayoría, benéficos, ya que influyen directamente en las cualidades organolépticas del queso y podrían tener un efecto probiótico, lo cual le atribuye nuevas utilidades al lactosuero de queso Paipa. 


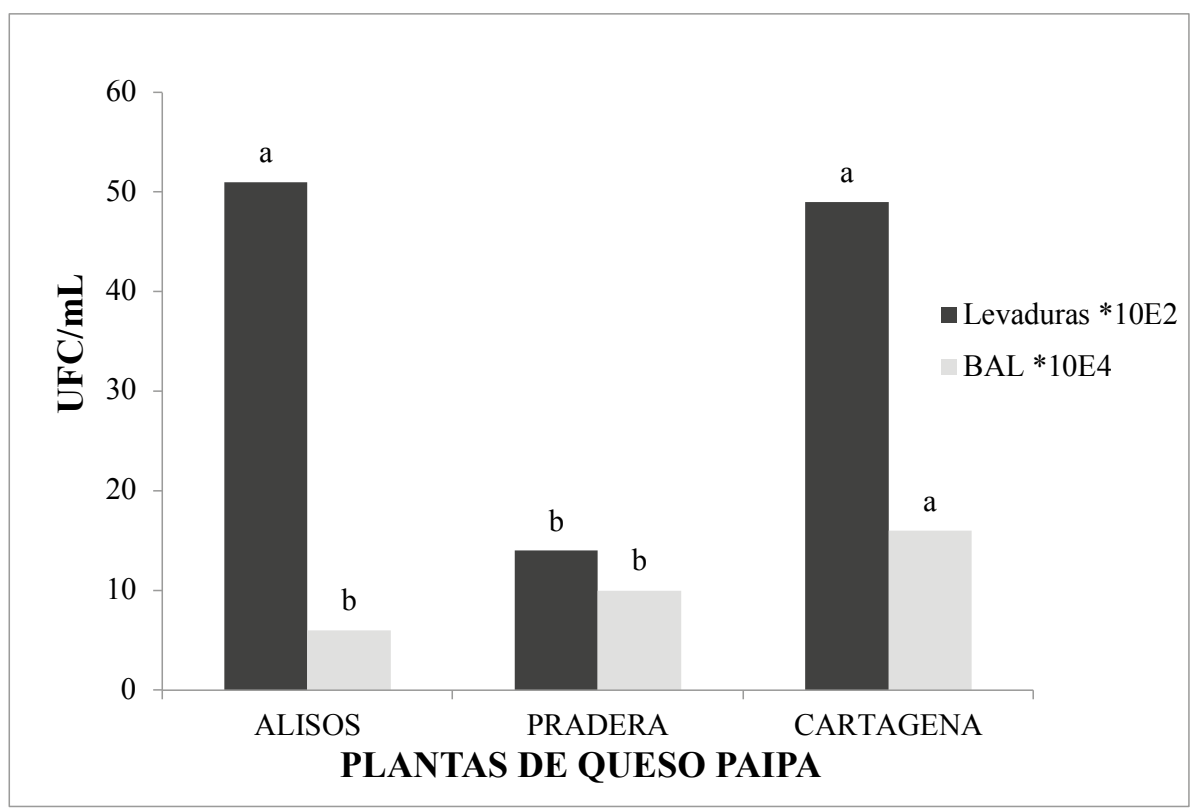

Fig. 1. Caracterización microbiológica de levaduras $\times 10^{2}$ y $B A L \times 10^{4}$ en lactosuero de tres plantas productoras de queso Paipa. Promedios seguidos de letras iguales no presentan diferencias significativas según prueba de Tukey $(\mathrm{P} \leq 0,01)$.

Otro aspecto a tener en cuenta son las múltiples aplicaciones industriales del lactosuero de queso Paipa, por sus propiedades físico-químicas y microbiológicas, en procesos fermentativos. Actualmente, existen varias alternativas biotecnológicas que usan el suero lácteo como medio de cultivo, aprovechando su composición química para la elaboración de distintos productos en la industria alimentaria y reduciendo el problema ecológico que generan sus componentes.

Diferentes estudios $(16,17)$ proponen como opción que las plantas de tratamiento biológico del suero lácteo utilicen las levaduras para reducir la carga de contaminantes y convertir la lactosa en biomasa microbiana; pero sería interesante implementar esta tecnología de tratamiento de este residuo no solo para disminuir la demanda química y biológica de oxígeno, sino también para obtener biomasa de alto contenido proteico y vitamínico que pueda ser utilizada como complemento dietario $(18,19)$.

Actualmente, la producción de proteína es insuficiente para la alimentación, y una alternativa a este problema es desde hace varios años la producción de proteína de levadura a través de procesos de fermentación (20). Estos procesos pueden usar fuentes de carbono económicas, como lactosuero, un microorganismo para producir biomasa y, por lo tanto, proteína de levadura. Este proceso puede ser descrito como una reacción bioquímica de células y lactosa para producir células microbianas (biomasa) como principal producto (21).

\section{Conclusiones}

Los principales factores que afectan la calidad en la composición fisicoquímica y microbiológica del lactosuero obtenido de la elaboración de queso Paipa se relacionan, muy posiblemente, con la calidad inicial de la leche con la que se elabora el producto y con el tipo de almacenamiento y manipulación que se le da al suero. Los sueros provenientes de las plantas de queso Paipa presentaron una composición similar a la de los sueros dulces; sin embargo, no presentaron buena calidad sanitaria.

Es necesario que los productores estandaricen los procesos de elaboración de queso Paipa y establezcan sistemas que garanticen las buenas prácticas de manufactura y un manejo sanitario de los sueros, para así mejorar la calidad del lactosuero, ya que no 
se cumplieron con los parámetros de conteo total de mesófilos aerobios y coliformes fecales y totales, establecidos por la norma del Ministerio de Salud de Colombia.

El manejo inadecuado del coproducto lactosuero del queso Paipa puede llegar a generar grandes problemas de índole ambiental en el departamento de Boyacá, por lo que se hace necesario establecer estrategias y alternativas productivas para el uso y aprovechamiento de esta materia prima. El lactosuero se constituye en una oportunidad de desarroIlo del sector lácteo e industrial, al ser un sustrato relativamente fácil de degradar que lo convierte en una alternativa para su uso como medio de cultivo en procesos biotecnológicos en la elaboración de distintos productos en la industria alimentaria.

\section{Agradecimientos}

Los autores agradecen a la Gobernación de Boyacá por la financiación del proyecto mediante convocatoria 733 de 2015 de Colciencias; también a los grupos de investigación GIBNA y Catálisis, de la Universidad Pedagógica y Tecnológica de Colombia, por todo el apoyo y la colaboración en el desarrollo del trabajo.

\section{Referencias}

(1) Ramírez-Navas J. Diseño de procesos en Industria Láctea: Transformación de lactosuero. Universidad Mariana. Investigación aplicada a la Ingeniería de Procesos, 2015.

(2) Castillo M., Jordán M., Abellán A., Laencina J., López M. Tecnología de aprovechamiento de lactosuero. Revista Española de Lechería, 1996; 24-30.

(3) Onwaulata $\mathrm{Cl}$., Hunt PJ. Whey processing Functionality and Health Benefits. Singapur: Wiley-Blackwell, 2008; 15-24.

(4) Paredes Montoya P., Chávez Martínez A., Rodríguez Figueroa JC., Aguilar Palma N., Rentería Monterrubio AL., Rodríguez Hernández G. Características fisicoquímicas y microbiológicas de suero de leche de queso Chihuahua. Investigación y Ciencia de la universidad Autónoma de Aguascalientes, 2014; 22 (62): 1116.

(5) Observatorio de Ciencia y Tecnología, «PEDCTI "Proyectos en CTel para el sector agroindustrial de Boyacá -2022"», Bogotá, 2012.

(6) Klotz B. Suero lácteo, clave en la innovación de alimentos. (3 de agosto de 2014). Recuperado el 20 de junio de 2018 de Portafolio. Disponible en: http://www.portafolio.co/economia/finanzas/ suero-lacteo-clave-innovacion-alimentos-61526.

(7) Resolución 02310 de 1986. Procesamiento, composición, requisitos, transporte y comercialización de los derivados lácteos. Ministerio de Salud. (1986).

(8) Abaigar A. El lactosuero en la alimentación del ganado porcino. ITG Ganadero, 2009; 13-17.
(9) Guerrero WJ., Gómez CA., Castro J., González CA., Santos EM. Caracterización fisicoquímica del lactosuero en el Valle de Tulancingo. En: XII congreso de Ciencia y Tecnología de Alimentos, 2010.

(10) Spreer E. Lactología industrial. Zaragoza (España): Editorial Acribia, 1991.

(11) Alava C., Gómez de Illera M., Maya J. Caracterización fisicoquímica del suero dulce obtenido de la producción de queso casero en el municipio de Pasto. Rev. Colomb. Investig. Agroindustriales. 2014; 1(1): 23-32. DOI: https://doi.org/10.23850/issn.24220582.

(12) Jinescu C, Aruş VA, Pârvulescu OC, Nistor ID. Modelling of Batch Lactic Acid Fermentation in the Presence of Anionic Clay. Food Technology and Biotechnology. 2014; 52(4): 448-458. doi:10.17113/ftb.52.04.14.3553.

(13) Callejas Hernández J., Prieto García F., Reyes Cruz VE., Marmolejo Santillán Y., Méndez Marzo MA. Caracterización fisicoquímica de un lacto suero: Potencialidad de recuperación de fósforo. Revista Acta Universitaria, 2012; 22(1): 11-18.

(14) Fox PF., Guinee TP., Cogan TM., McSweeney PL. Fundamentals of cheese science. New York: Springer, 2017. DOI: https://doi. org/10.1007/978-1-4899-7681-9.

(15) Neira E., Silvestri J. Análisis del proceso de ordeño y de la calidad higiénica de la leche utilizada en la fabricación del queso Paipa en el municipio de Paipa (Boyacá), Colombia. Revista de Investigación Universidad de la Salle, 2006; 6(2): 163-170.

(16) Ghaly A., Kamal M. Submerged yeast fermentation of acid cheese whey for protein production and pollution potential reduction. Water Research, 2004; 38(3): 631-644.

(17) Urbina C., Juárez Ramírez C., Ruiz Ordaz N., Galíndez Mayer J. Selección de un cultivo mixto de levaduras para el tratamiento biológico del suero lácteo. Tecnología Láctea Latinoamericana, 2000; 44-47.

(18) De Palma Revillion, JP., Brandelli A., Záchia Ayub MA. Production of yeast extrat from whey using Kluyveromyces marxianus. Brazilian archives of biology and technology, 2003; 46(1): 121128. DOI: https://doi.org/10.1590/S1516-89132003000100017.

(19) Novoa M., Martinez-Palacios C., Olivera-Castillo L. Utilization of torula yeast (Candida utilis) as a protein source in diets for tilapia (Oreochromis mossambicus Peters) fry. Olvera Aquaculture Nutrition, 2002; 8(2): 257-264.

(20) Mawson. J. Fermentation of whey. Encyclopedia of Food Sciences and Nutrition. Academic Press, 2003; 6157-6163.

(21) Ghaly A., Kamal M., Correia L. Kinetic modelling of continuous submerged fermentation of cheese whey for single cell protein production. Bioresource Technology, 2005; 96(10): 1143-1152.

(22) Diaz-Monroy BL., Iglesia AE., Valiño E. Consorcios microbianos con actividad ácido-láctica promisoria aislados desde inoculantes bacterianos nativos para ensilajes. Revista Ciencia y Agricultura, 2014; 11(1): 17-25. DOI: https://doi. org/10.19053/01228420.3484.

(23) Mas-Toro D., Martínez-Aguilar Y., Rodriguez-Bertot R., Betancur-Hurtado C., Rosabal-Nava O. Effect of dietary supplementation with Morinda citrifolia on productivity and egg quality of laying hens. Revista Ciencia y Agricultura, 2015; 12(2): 7-12. DOI: https://doi.org/10.19053/01228420.4348.

(24) Flores-Mancheno LG., García-Hernández Y., Proaño-Ortiz FB., Caicedo-Quinche WO. Evaluación de tres dosis de un preparado microbiano, obtenido en Ecuador, en la respuesta productiva y sanitaria de cerdos en posdestete. Revista Ciencia y Agricultura, 2015; 12(2): 59-70. DOI: https://doi. org/10.19053/01228420.4392. 